\title{
The Effect on Elementary Science Education Based on Student's Pre-inquiry
}

\author{
Houn Tae Kang ${ }^{1}$, Suk Goo Noh ${ }^{2, *}$ \\ ${ }^{1}$ Gochon Elementary School, South Korea \\ ${ }^{2}$ Gyeongin National University of Education, South Korea
}

Copyright $\subset 2017$ by authors, all rights reserved. Authors agree that this article remains permanently open access under the terms of the Creative Commons Attribution License 4.0 International License

\begin{abstract}
In this research, after extracting the pre-inquiries (student-level question) for which students had curiosity in the elementary science and analyzing their correlation with the elementary science curriculum, highly correlated inquiries (meaningful pre-inquiries) were selected and applied in class. After organizing an experiment group and a controlled group with one each class of 6th grade in two elementary schools which showed homogeneity in prior research. This study collected pre-inquiries from the experiment group through a questionnaire and together with a science education experts selected inquiries significant to the elementary science curriculum. The selected pre-inquiries were used for each class and its activity (question -resolution class) to accomplish the class goal. Through this research class, this study conducted T-test, mean-difference test, in order to compare the difference by period and group in science process skills and science-related affective domain. In the result of the science process skills, the controlled group showed 16.20 score while the experiment group showed 17.70 so that the experiment group showed higher score and it was a significant difference $(\mathrm{p}<.05)$. Also, for the sciencerelated affective domain, the experiment group showed significantly higher scores compared to the controlled group in general $(\mathrm{p}<.001)$. This study explored the educational implication in organizing elementary science curriculums in consideration of the demanders such as what subject students have interest in or feel curious about.
\end{abstract}

Keywords Student's Inquiry, Question, Science Process Skills, Science-related Affective Domain

\section{Introduction}

In modern society, all goods and services are produced and supplied reflecting the thinking and attitude of consumers. In other word, everything is made, customized and operated around consumers. However, in the field of education, learning is conducted with a set of curriculum and textbooks regardless of learner ' thoughts or inquiries. How much does education understand the students as consumers? Many science education experts have tried to make the science education curriculum and textbooks. But, they don't actually know what the students wanted to know. The student-centered education requires personalized learning to take place. Science class is composed by questioning the natural and social phenomenon of students as a starting point of scientific inquiry and organizing and creating their thoughts and ideas. In a constructivist perspective that emphasizes the role of students in teaching-learning, teachers should consider the nature and extent of students' thinking or understanding before teaching the lesson or teaching the next step (Scott et al., 1994) [9]. However, in a limited classroom, it is almost impossible for a teacher to grasp the degree of thought or understanding that a student has, and as an alternative, students can ask questions (Maskill \& de Jesus, 1997) [20]. Donaldson (1978) [4]stated that student questions not only provide insight into the student's inner world, but also provide the teacher with a significant amount of information about the student's reasoning. Student questioning is a good guide to what a student wants to know (Elstgeest, 1985) [5], which is a way to get information about the preconceptions students already have and their level of understanding (Maskill \& de Jesus. 1997) [20]. Based on the students' inquiries, the teacher will know what the student wants and will be able to get a lot of data about the student's level of thinking and prepare for the next class (Kim et al., 1999) [17]. Also, Student's inquiries have an important meaning in that they link learning and thinking. Students will think through questions, seek meaning, and relate new ideas to familiar concepts (King, 1994) [18]. And the student's inquiries have an important role to enable the basic elements of science and science process skills (Chin \& Brown, 2002) [11]. When students ask questions and find meaning, they associate new ideas with familiar concepts (King, 1994) [18]. This can be thought of as a step in the process of information processing (White, 1988) [26], several studies have reported that students' inquiries-explanatory in learning activities are helpful in learning (Cuccio-Schirripa \& Steiner, 2000) [12]. 
In this way, the importance of learner questions has been acknowledged, and studies related to students' questions have been made in a wide variety of ways. However, the research on student's question is mostly about the intermediate and post-learning question, and the research related to the question before the learning is very rare. Student's pre-inquiry is learning to diagnose the starting point of the learner and to link the new information to what the learner knows, and there are factors that can affect learning. In addition, the teacher must identify the student's thinking and teach the students according to the student's needs (Ausubel, 1968) [1]. The questions that students have before they learn can help students to explore and set up inquiry problems and to engage in inquiry activities and to encourage students' creative critical thinking and active participation in inquiry (Gott \& Duggan, 1995) [7]. In addition, students 'self-generated questions improve students' ability to think and manipulate information, so teachers must engage in class with an interest in the questions that students make (Wellington \& Wellington, 1962) [25]. Thus, the researchers will analyze the pre-inquiries about the scientific needs of students and learners to evaluate the effect, which is applied to student in the class. Also, when configuring science curriculum, and to provide a basis for constructing the curriculum and textbooks, the researchers considered the aspects of the student.

The purpose of this research, is to extract the pre-inquiries (student-level questions) for which students had curiosity in the elementary science. And analyze their correlation with the elementary science curriculum, highly correlated inquiries were selected and applied in class. When learning and teaching science based on student's pre-inquiries, find out the effect of the student. This study was guided by three questions:

1) What type of 6th grade students who have pre-inquiries at the science?

2) When the class uses the student's pre-inquiries, what does impact on science process skills of a student?

3) When the class uses the student's pre-inquiries, what does impact on a science-related affective domain of a student?

\section{Review Related Literature}

In order for a student to acquire knowledge through a question, a self-inquiry must be made about the phenomenon or principle itself first. After the question has been generated, the student can acquire scientific concepts, knowledge, etc. through means of questions.

\subsection{Definition of Scientific Inquiries}

Simpson et al. (1981) [23] defines the question of recognizing the contradiction between what we observe and what we know, and extracting unstable problems, doubts, and uncertainties based on them. Christenbury \& Kelly (1983) [3] is a scientific inquiry that raises questions those are created when new situations encountered by students challenge their curiosity. The question is an expression of uncertainty and a true answer with the intention of eliminating or reducing uncertainty (Dillon, 1988). Lawson (1995) [8] defines scientific questions as being generated when faced with questionable or surprising phenomena that can't be explained by current knowledge. Spargo \& Enderstein (1997) [24] define scientific inquiries when faced with various situations related to natural phenomena. Based on the viewpoint of scholars, it can be said that scientific inquiries are generated by unstable problems, suspicions, and uncertainties that can't be explained by the curiosity and natural knowledge of natural phenomena.

\subsection{Classification of Student Inquiries Type}

Bloom (1956) [2] categorized the question types classified as knowledge questions, understanding questions, application questions, analysis questions, comprehensive questions, and evaluation questions based on six categories of cognitive level. Knowledge questions are questions that require information or recall of knowledge at the lowest level, the question of understanding is a question that must go beyond the recall of information, have a sufficient personal understanding of the information, and explain or re-state the facts related to the answer to the question. Application questions are those that require application of the learned information, and analytical questions are those that require critical thinking and in-depth thinking. Comprehensive question is a top-level question that demands creative and creative thinking. The evaluation question is a question that belongs to a higher-level question with an analysis or a comprehensive question, and a question about an idea or concept about an advantage, solution, esthetic work, etc. The question types of Sadker \& Cooper (1974) [22] were classified as low and high. Low-level questions are questions that require a response depending on memory or recall, and high-level questions are questions that require thought processes to respond. Chin \& Brown (2002) [11] classified the questions into basic information questions and curiosity questions according to type. Basic information questions are facts, procedural questions, and curiosity questions are further divided into understanding, prediction, anomaly detection, application, and planning questions. Cuccio-Schirripa \& Steriner (2000) [12] divided the questions into four levels. A Level 1 question is a yes or no question that requires an answer or requires a few words of answers, Level 2 questions are questions that require answers that consist of descriptions using factual descriptions and comparisons. Level 3 questions are questions that can be answered through experiments, Level 4 questions are questions that can be answered through experiments, which means that the variables are high-level questions that are specifically and manipulatively included in the question. Good (1995) [6] classified the types of student questions into nine categories. A descriptive question is a question requiring meaning or reason, an informative question is a question requiring only detailed and factual information, a 
procedural question is a question of interest in the procedure, and a confirmatory question is a confirmation of knowledge or answers Is a question that requires. Curious questions are those questions that are not directly related to the class, clarifying questions are questions that require a clear explanation of the tasks, recreational questions are questions that are drawn to the other side of the class, Type questions are questions that are related to the class and attract or show interest to others. Class-related interest type questions are not related to the class but are merely interested. The type of King (1994) [18] was categorized as fact question and thinking question according to the knowledge construct level. Thinking questions were again divided into understanding questions and integrated questions. In fact, the question is simply a question that relies solely on the re-statement of knowledge, and the thinking question is a question that has the characteristic of assimilating knowledge or requiring the integration of knowledge of understanding questions.

\subsection{Importance of Student Inquiries in Science Class}

The inquiry is the mother of research, invention, and discovery. Science education should be done from students' inquiries as a starting point. In order for constructivist learning to take place, it is important not to look for answers of the questions that teachers or other people present, but to emphasize the students' self-questioning and expressing their thoughts and exploring. Dillon (1982) [13] suggested that the inquiries raised by the students themselves are more likely to stimulate students' thinking than the questions thrown by teachers. Questioning in science is the core of scientific inquiry (Chin \& Brown, 2002) [11]. In addition, scientific inquiry requires problem solving and critical thinking skills. When a learner is at a high cognitive level, asking is itself considered an essential aspect of problem solving (Pizzini \& Shepardson, 1991) [21]. It is important to gather students' inquiries, knowing what kind of knowledge a student is trying to learn rather than determining what knowledge is necessary for the student and what knowledge is appropriate for the ideal of education. In other words, the students' inquiries are the best way and way to provide teachers with the learner's current status, knowledge level, interests, and passion for study. Maskill \& Pedrosa de Jesus (1997) [20] suggested that students ' inquiries should help teachers to understand the concepts of students' prior knowledge and establish effective teaching strategies. Students are encouraged to inquire into science learning through their own questions. Woodward (1992) [27] suggested that the student's inquiry provides an opportunity for the teacher to gain some insight into the student's thoughts and concepts. These questions are not only interpreted in terms of the teacher's point of view, but also create meaningful and positive effects in the learning process of students themselves. Students' self-inquiry problem-setting and set-up activities facilitate students' creative, critical thinking and active participation in inquiry (Gott \& Duggan, 1995) [7]. Students' Inquiries are said to be one of systematically organized thinking processes such as student problem solving, critical thinking, and creative thinking (Cuccio-Schirripa \& Steiner, 2000) [12]. In addition, students' inquiries formation is a process that allows students to look back at the content of the lessons themselves, and helps them to improve their thinking skills by reflecting on their own reflection and reflection during the question process (White, 1992) [26].

\section{Methods of Study}

The subject of this study is elementary school $6^{\text {th }}$ grade students in South Korea. First of all, Science educators, and fellow teachers, we selected only pre-inquiries that were closely related to the 'Acid and Base' of the $6^{\text {th }}$ grade of elementary students and that could be helpful for learning. Pre-inquiries are questions that students usually wonder or want to know about the topic and content of a unit to learn based on what they have learned previously and the key concepts and phenomena of the unit to be studied. Among the pre-inquiries proposed by the students, they are said to be meaningful pre-inquiries that are deeply related to the curriculum and are considered to be effective for students in applying science classes. These meaningful pre-inquiries were made in consultation with science curriculum specialists and fellow teachers.

So, organizing an experiment group and a controlled group with one each class of 6th grade in two elementary schools which showed homogeneity in pretest. The experiment group consisted of 33 students, 15 boys and 18 girls from the $6^{\text {th }}$ grade elementary school in South Korea. And the lessons were made using meaningful pre-inquiries about 'acid and base' unit. The control group consisted of 29 students, 12 boys and 17 girls. The class was taught according to general teaching methods using elementary school science textbooks and tutorials. Also, in both the experimental group and the control group, all the teachers were working as teachers with at least 5 years of teaching experience and less than 10 years, to improve the research verification effect by minimizing the difference according to the teacher's career. In order to investigate the students' meaningful pre-inquiries, and to see how the lessons using the lessons affect the science process skills and a science-related affective domain of the students in the experimental group, the experimental design was conducted as shown in Table 1.

Table 1. Experimental Design

\begin{tabular}{|c|c|c|c|}
\hline G1 & O1 & X1 & O2 \\
\hline G2 & O3 & & O4 \\
\hline
\end{tabular}

G1: Experiment Group; G2: Controlled Group

$\mathrm{X} 1$ : Class using the student's pre-inquiries

O1 O3: pretest (science process skills, science-related affective domain) O2 O4: posttest (science process skills, science-related affective domain)

This study collected student's pre-inquiries from the experiment group through a questionnaire and together with a science education experts selected inquiries significant to the elementary science curriculum. Through this study, the students showed meaningful pre-inquiries as learning 
problems and activities. And the selected student's pre-inquiries were used for each learning and teaching and its activity (question-resolution class) to accomplish the class goal. The research process is shown in Figure 1.

Through this research class, this study conducted T-test, mean-difference test, in order to compare the difference by group in science process skills and science-related affective domain. The science process skills test was conducted using the Test of Science Process Skills (TSPS). The TSPS test was developed by Kwon \& Kim (1994) [19] to be applied from the $5^{\text {th }}$ grade of elementary school to the $3^{\text {rd }}$ grade of middle school. All 30 items were classified into basic inquiry ability and integrated inquiry ability. It was developed to measure five basic science process skills: observation, measurement, classification, prediction, and inference.

\begin{tabular}{c}
$\begin{array}{c}\text { Grade } 6 \text { Before studying 'Acid and Base', } \\
\text { the student was asked the student's pre-inquiries }\end{array}$ \\
$\downarrow$ \\
$\begin{array}{c}\text { First Classification: Together with peer teachers, } \\
\text { select pre-inquiries that can be used significantly in class }\end{array}$ \\
$\downarrow$ \\
Second class: Consult with the science education \\
specialist to determine the final highly correlated \\
inquiries (meaningful pre-inquiries) \\
$\downarrow$ \\
\hline The 'Acid and Base' class using $6^{\text {th }}$ grade experiment \\
group with meaningful pre-inquiries
\end{tabular}

Figure 1. Meaningful Pre-Inquiries Analysis Process

And the integrated science process skills were developed to measure five variables: data processing, data interpreting, hypothesizing, controlling variables, and generalization. There are 3 items in each area, and each item is scored as 1 point. This test was conducted before and after the instruction using pre-inquiries. The average difficulty of the questionnaires was 0.61 , the mean discrimination was 0.41 , and the reliability was 0.76 . The science-related affective domain evaluation was conducted by Kim (1997) [16] using the Reckitt scale 48 items developed in the development of the evaluation system of the affective domain characteristics related to science at the national level. The science-related affective domain characteristics used in this study have the same meaning as the 'science-related attitudes' used in this study. The questionnaire consisted of a total of 48 items, Cronbach's á. 96. This study analyzed statistical data collected through data coding and data cleaning process and analyzed using SPSS statistical package program. In order to investigate the differences in students' science process skills and science-related affective domain, we conducted t-test, which is the mean difference test.

\section{Results and Discussion}

The question types of Good (1995) [6] were used to analyze students' pre-inquiries types before class. Question types include explanation, information, procedural, confirmation, and non-task curiosity questions.

\subsection{Type Student's Pre-Inquiries}

Explanation questions are questions that ask for meaning or reason to help them understand the concept. Information questions are factual, require very detailed information or information, and procedural questions are questions that concern the process of the phenomenon. Confirmation questions are questions that require confirmation of the completed knowledge, and non-task curiosity questions are questions that are created by the student's simple curiosity, irrespective of class. A total of 52 questions were asked by the students before learning the 'Acid and Base' unit in the elementary science material area. As a result of examining the frequency of each question according to the classification type of Good (1995), five for each type of question, there were 10 explanation inquiries $(19.2 \%), 29$ information inquiries $(55.7 \%), 7$ procedural inquiries $(13.4 \%), 2$ confirmation inquiries (3.8\%), 4 non-task curiosity inquiries $(7.9 \%)$. In the acid and base unit, the students had the most informative questions, followed by descriptive, procedural, curious, and confirmative questions. Among the 52 pre-inquiries presented by the students, 7 fellow teachers and 1 science education specialist were selected and 24 meaningful pre-inquiries related to the 'Acid and Base' unit and applicable to the class were selected. According to the classification of Good (1995), the meaningful pre-inquiries was classified by type and the frequency was examined. The results were as follows: four types of explanation inquiries (16.7\%), Information inquiries $(45.8 \%), 4$ procedural inquiries (16.7\%), 1 confirmation inquiries $(4.1 \%)$ and 4 non-task curiosity inquiries $(16.7 \%)$. In the case of meaningful pre-inquiries, the number of information-type inquiries was the greatest, as opposed to the pre-inquiries of all students, but unlike the pre-inquiries, explanation, procedural, and non-task curiosity inquiries all accounted for the second and the number of confirmation inquiries was the smallest. In the case of meaningful pre-inquiries, the number of information-type questions was the greatest, however, unlike pre-questions, descriptive questions, procedural questions, and curiosity questions all accounted for the second largest number of questions in the same number and confirmatory questions showed the least number.

\section{$<$ Meaningful pre-inquiries - Confirmatory Questions $>$}

.Why do I feel slippery when I touch alkaline solution? What kind of substance causes this?

.Why is the acid solution dangerous, for what ingredients?

.Why does acid rain have a lot of negative effects on us?

What causes acid rain?

$<$ Meaningful pre-inquiries - Informative Question>

What substances are contained in acidic or alkaline solutions?

.It is acidic (lemon) that can be eaten, and it is in acid solution which it should not eat. How much acid concentration can we eat? 
. What ingredients in soap or detergent remove dirt?

. Are there any acidic or alkaline foods?

. Is it harmful to our bodies when we touch acidic and alkaline solutions?

.Was there no acid rain in the past?

. Is there any alkaline rain?

. Is there anything good about acid rain?

.Vinegar is very sour, what kind of substance cause that?

.Does acidic taste sour? Can alkaline become soap?

.What happens if I put acidic and alkaline substance into water

$<$ Meaningful pre-inquiries - Procedural Questions $>$

.When can acidic and alkaline be used?

.How do you distinguish between acidity and alkaline?

. How can I remove acid rain

.The process of acid rain

$<$ Meaningful pre-inquiries - Confirmatory Question $>$

.Is it true that acidic solution includes Coke and Sprite and alkaline solution Ion drink?

$<$ Meaningful pre-inquiries - Curiosity Questions $>$

. Is there any such thing that is neither acidic nor alkaline?

.How do you distinguish between power aids and glass cleaners?

.If I mix acidic solution and alkaline solution together, does it bring out explosion?

. Will not the new material appear when mixing the proportions of the acid solution and the basic solution?

Table 2 shows the results of analyzing the question types of these students' pre-inquiries and meaningful preinquiries.

In addition, the percentage of meaningful pre-inquiries for pre-inquiries is also shown. This shows that the level of students' inquiries is not related to the types of questions students make. Non-task curiosity and procedural questions are few in number, but they are not of low quality, so you can see that they are highly used in class.

Table 2. Student's Pre-Inquiries Type

\begin{tabular}{|c|c|c|c|c|c|}
\hline & \multicolumn{2}{|c|}{ Pre-Inquiries } & \multicolumn{2}{c|}{$\begin{array}{c}\text { Meaningful } \\
\text { Pre-Inquiries }\end{array}$} & $\begin{array}{c}\text { Meaningful } \\
\text { Pre-inquiries } \\
\text { Pre-inquiries }\end{array}$ \\
\cline { 2 - 6 } & No & $\%$ & No & $\%$ & $\%$ \\
\hline $\begin{array}{c}\text { Explanation } \\
\text { Questions }\end{array}$ & 10 & 19.2 & 4 & 16.7 & 40 \\
\hline $\begin{array}{c}\text { Information } \\
\text { Questions }\end{array}$ & 29 & 55.7 & 11 & 45.8 & 38 \\
\hline $\begin{array}{c}\text { Procedural } \\
\text { Questions }\end{array}$ & 7 & 13.4 & 4 & 16.7 & 57 \\
\hline $\begin{array}{c}\text { Confirmation } \\
\text { Questions }\end{array}$ & 2 & 3.8 & 1 & 4.1 & 50 \\
\hline $\begin{array}{c}\text { Non-Task } \\
\text { Curiosity } \\
\text { Questions }\end{array}$ & 4 & 7.9 & 4 & 16.7 & 100 \\
\hline Total & 52 & 100 & 24 & 100 & 46 \\
\hline
\end{tabular}

\subsection{Science Process Skills}

When we look at the difference of scientific process skills by group in the case of the measuring, 2.13 points in the controlled group and 2.39 points in the experimental group showed a significant difference $(p<.05)$. In the case of inferencing, the controlled group showed 1.60 points and the experimental group showed 1.85 points, which showed a significant difference $(p<.05)$. In the case of controlling variables, the controlled group showed 1.23 points and the experimental group showed 1.64 points, which showed a significant difference $(p<.05)$. In the generalization, the controlled group showed 1.17 points and the experimental group showed 1.45 points, which showed a significant difference $(p<.05)$.

Table 3. Science Process Skills Posttest $t$-test

\begin{tabular}{|c|c|c|c|c|}
\hline & \multicolumn{2}{|c|}{ Mean (SD) } & \multirow{2}{*}{$t$} & \multirow{2}{*}{$p$} \\
\hline & Experiment Group & Controlled Group & & \\
\hline Observing & $1.73(0.876)$ & $1.97(0.809)$ & 1.124 & 0.066 \\
\hline Classifying & $2.03(0.883)$ & $2.17(0.699)$ & .675 & 0.502 \\
\hline Measuring & $2.39(0.747)$ & $2.13(0.730)$ & 2.397 & $0.016^{*}$ \\
\hline Inferencing & $1.85(0.755)$ & $1.60(0.855)$ & 2.225 & $0.022 *$ \\
\hline Predicting & $2.15(0.906)$ & $2.00(0.695)$ & .739 & 0.462 \\
\hline Data Processing & $1.64(0.822)$ & $1.43(0.817)$ & .982 & 0.330 \\
\hline Data Interpreting & $1.30(0.918)$ & $1.17(0.747)$ & .643 & 0.523 \\
\hline Hypothesizing & $1.52(0.870)$ & $1.33(0.922)$ & .805 & 0.424 \\
\hline Controlling Variables & $1.64(0.962)$ & $1.23(1.073)$ & 2.572 & $0.012 *$ \\
\hline Generalization & $1.45(0.833)$ & $1.17(0.986)$ & 2.256 & $0.021 *$ \\
\hline Total & $17.70(4.231)$ & $16.20(3.643)$ & 2.498 & $0.013 *$ \\
\hline
\end{tabular}

$* p<.05$ 
Overall, in the case of science process skills, the controlled group showed 16.20 points and the experimental group showed 17.70 points. The experimental group showed a significant difference $(p<.05)$. These results show that science teaching using meaningful pre-inquiries improves students' scientific process skills compared to traditional science lessons using textbooks. In particular, it shows that measurement, inference, controlling variables, and generalization show greater improvement can be. After conducting the lesson using meaningful pre-inquiries, differences between groups of scientific process skills are shown in Table 3. It can be seen that the science class using the pre-inquiry helps the student to improve various skills of science process skills. Science process skills are often used in conjunction with multiple process skills, rather than just one capability of the process skill. In other words, when doing science lessons, process skills such as observing and classifying do not occur alone, but observing and inferencing, observing and classifying often occur together. In particular, in the case of a science class using pre-inquiries, process skills such as measuring, inferencing, controlling variables, and generalization of the learning object are closely linked and utilized in order to solve the questions presented by themselves. This process can be interpreted as the ability of science process skill to grow.

\subsection{Science-Related Affective Domain}

In the case of science awareness, a sub-element of science-related affective domain by group, 3.12 in the controlled group, and 3.72 in the experimental group. It can be seen that a difference has occurred. In the case of the awareness of science education, 2.66 points for controlled group and 3.66 point for experiment group showed significant difference. And in the case of awareness for a job related to science, 3.22 points for the controlled group and 3.77points for the experimental group showed significant differences. As a whole, in the case of science-related affective domain, the controlled group showed a difference of 3.05 points and the experimental group showed 3.64 points. Therefore, it can be seen that students' science-related affective domain has improved after the science class using meaningful pre-inquiries. After conducting the lesson using meaningful pre-inquiries, differences between groups of awareness of science are shown in Table 4.

When we look at the difference of the group after the interest in science, a sub-element of interest in science is by group, 2.56 points for the controlled group and 3.59 points for the experiment group. In the case of interest in science learning, 2.66 points in the controlled group and 3.62 points in the experimental group showed significant differences. In the case of interest in science-related activities 2.50 points for controlled group and 3.10 points for experiment group showed significant difference. Interest in science-related job was also high after the experiment, and there was no significant difference in the science and anxiety. Overall, the interest in science was 2.73 points for the controlled group and 3.36 points for the experimental group, indicating a significant difference. Thus, it can be seen that the interest in science has improved even more after the science class using meaningful pre-inquiries. After conducting the lesson using meaningful pre-inquiries, differences between groups of interest in science are shown in Table 5.

As for the group differences in the scientific attitude, it was found that there was a significant difference in the sub-variables curiosity with 2.97 points in the controlled group and 3.80 points in the experimental group. In the case of permission, the controlled group showed 3.08 points and the experimental group showed 3.58 points. In the case of criticism, the controlled group showed 2.93 points and the experimental group showed 3.26 points. Cooperative, volunteering, perseverance, and creativity were significantly higher in the experimental group. The overall science attitude was 2.97 points for the controlled group and 3.49 points for the experimental group, indicating a significant difference. Therefore, it can be seen that the students' attitudes toward science have improved after the science class using meaningful pre-inquiries, and it can be seen that the experimental group is significantly improved compared to the comparative group in the whole of the science-related affective domain as well. After conducting the lesson using meaningful pre-inquiries, differences between groups of scientific attitudes and science-related affective domain are shown in Table 6.

Table 4. Awareness of Science Posttest $t$-test

\begin{tabular}{|c|c|c|c|c|}
\hline & \multicolumn{2}{|c|}{ Mean (SD) } & \multirow{2}{*}{${ }_{t}^{t}$} & \multirow{2}{*}{$\begin{array}{l}p \\
p\end{array}$} \\
\hline & Experiment Group & Controlled Group & & \\
\hline Awareness of Science & $3.72(0.63)$ & $3.12(0.38)$ & -4.49 & $0.00 * *$ \\
\hline Awareness of Science Education & $3.66(0.54)$ & $2.66(0.63)$ & -6.78 & $0.00 * *$ \\
\hline $\begin{array}{c}\text { Awareness for a Job Related to } \\
\text { Science }\end{array}$ & $3.77(0.60)$ & $3.22(0.42)$ & -4.19 & $0.00 * *$ \\
\hline $\begin{array}{l}\text { Awareness of the Science- Technology- } \\
\text { Society Interrelationship }\end{array}$ & $3.42(0.74)$ & $3.20(0.51)$ & -1.38 & 0.17 \\
\hline Total & $3.64(0.43)$ & $3.05(0.26)$ & -6.58 & $0.00 * *$ \\
\hline
\end{tabular}

$* * p<.01$ 
Table 5. Interest in Science Posttest t-test

\begin{tabular}{|c|c|c|c|}
\hline \multirow{2}{*}{} & \multicolumn{2}{|c|}{ Mean (SD) } & \multirow{2}{*}{$t$} \\
\cline { 2 - 4 } & Experiment Group & Controlled Group & \\
\hline Interest in Science & $3.59(0.80)$ & $2.56(0.82)$ & -5.05 \\
\hline Interest in Science Learning & $3.62(0.70)$ & $2.66(0.68)$ & -5.52 \\
\hline $\begin{array}{c}\text { Interest in Science-Related } \\
\text { Activities }\end{array}$ & $3.10(0.61)$ & $2.50(0.81)$ & -3.36 \\
\hline Interest in Science-related Job & $2.84(0.75)$ & $2.40(0.66)$ & -2.45 \\
\hline Science and Anxiety & $3.65(0.81)$ & $3.56(0.67)$ & $-0.00 *$ \\
\hline Total & $3.36(0.50)$ & $2.73(0.46)$ & 0.63 \\
\hline
\end{tabular}

$$
* * p<.01, * p<.05
$$

Table 6. Scientific Attitudes Posttest $t$-test

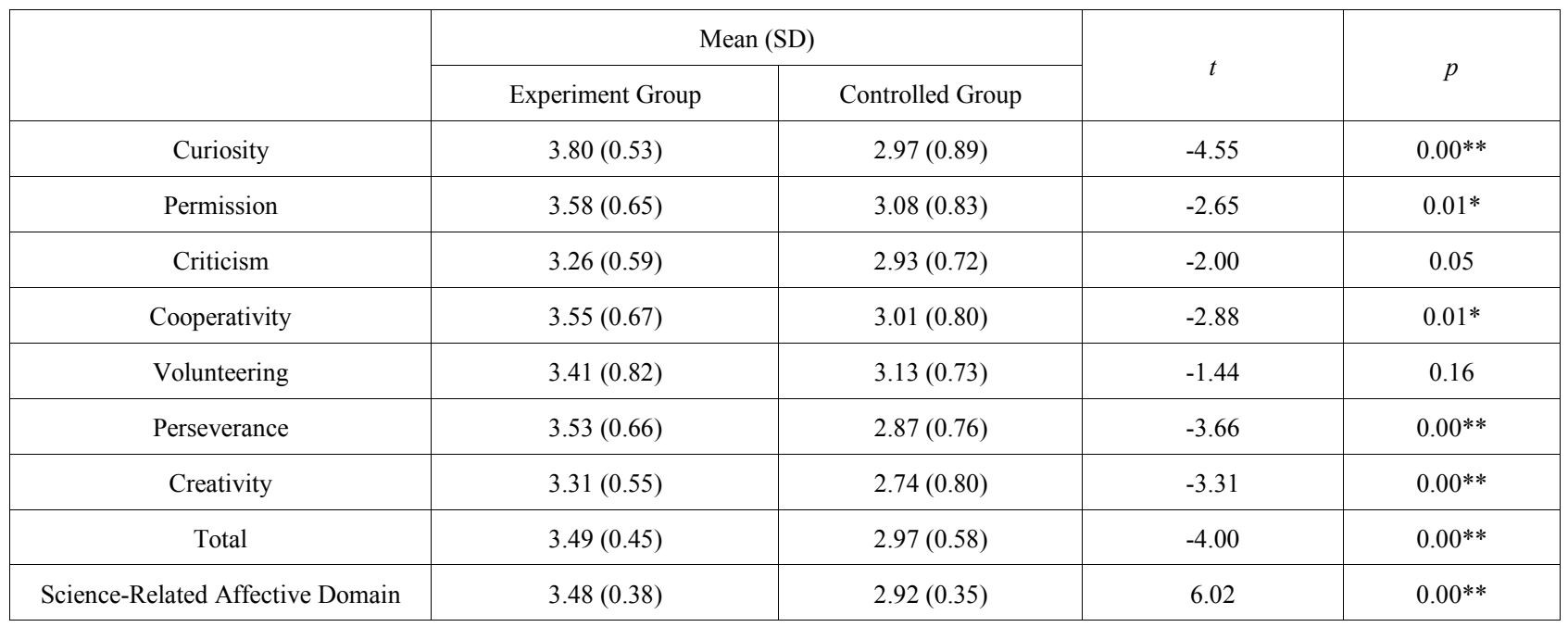

$* * p<.01, * p<.05$

The students' science-related affective domain after the science class using the pre-inquiry showed positivity in all aspects. As the lesson progresses using student's pre-inquiries, the students were highly interested in the class, and they were active in the class. Their awareness of science, perception of science learning, science-related activities, and science-related activities, science-related job were all high. These results can be interpreted as suggesting a way for students who are not interested in science and science learning to be more interested in and active in class. In addition, permission, cooperativity, perseverance, and creativity, all of which are important in the science-related affective domain, have a positive effect on the class using the pre-inquiries. Curiosity is the science-related affective domain that is most related to the pre-inquiry. Curiosity that the student usually has is linked with the learning topic, and the concrete question is the pre-inquiry. In addition, scientific communication skills were improved compared to previous times, while participating actively with interest in science class and experimenting with activity with group students. This development of communication ability can be interpreted as improvement with permission, cooperativity, perseverance. And. It can be interpreted that a more advanced thinking and creativity are developed by going through a lot of thought and discussion process to solve the problem presented by oneself.

\section{Conclusions and Suggestions}

In this study, students were asked about the pre-inquiries in the "Acid and Base" section of the $6^{\text {th }}$ grade elementary school, and then they were closely related to the science curriculum. The questionnaire was selected as meaningful pre-inquiries. The purpose of this study was to analyze the student's types of meaningful pre-inquiries and to investigate the effect of learner's science process skills and science-related affective domain. The results of this study are as follows: First, the information-type questions were the most pre-inquiries presented by students, followed by explanation, procedural, non-task curiosity, and confirmation questions. Through this, the level of pre-inquiries for elementary students was relatively basic, there were many inquiries based on facts, and there were many inquiries asking for information-related inquiries and explanations of learned knowledge. Given the level of 
elementary school students who are still lacking in science knowledge, it is difficult for students to ask abstract, high-dimensional questions. Students were able to see simple facts and information, a lot of questions about what they knew and the surrounding environment. Second, the number of informative inquiries was the most significant inquiries, which was a meaningful pre-inquiries based on the curriculum of science experts and colleagues, followed by explanation, procedural, and non-task curiosity inquiries. Based on this, it was shown that the level of student inquiries was not related to the types of inquiries students had. In the case of the pre-inquiries, Non-task curiosity inquiries and procedural inquiries were few, but the quality of the questions was not low. It can be seen that this type of inquiries is possible for all types of inquiries, not just information inquiries and explanation inquiries. Finally, the students' science process skills and science- related affective domain were improved by using meaningful pre-inquiries. In this way, analyzing the students' meaningful pre-inquiries and conducting the science lessons using them can show a positive learning effect for the students. Based on these results, we suggested that; first, teachers should not only analyze teaching materials such as curriculum and textbooks before class, but also understand and analyze student's thoughts by using student's pre-inquiries. And considering the level and interests of students, teacher can reconstruct the class to suit the level and needs of the students. Second, based on the pre-inquiries collected through this study, it is expected that the teaching-learning method of elementary school can be diversified and the class using meaningful pre-inquiries can be applied in elementary school field. Finally, the curriculum and textbooks are made up of a lot of educational experts, but they do not know what students are interested in learning. Therefore, it is necessary to construct the curriculum and the textbook considering the students' understanding of the learners who are the demanders of the education when constructing the curriculum and the textbook. Although this study was conducted for elementary school students in South Korea, it is anticipated that it will be possible for the elementary school students in many countries of the world to use the pre-inquiries to make effective teaching-learning.

\section{REFERENCES}

[1] Ausubel. D. Educational psychology: A cognitive view, New York: Holt, Rinehart \& Winston, 1968.

[2] Bloom, B. S. Taxonomy of educational objectives, Handbook I : Cognitive domain, New York: David Mc Kay Company, Inc., 1956

[3] Christenbury, L. \& Kelly, P. Questioning: A Path to Critical Thinking. Urbana, IL: National Council of Teachers of English, 1983.
[4] Donaldson, M. Children's Minds, Glasgow, Scotland: Fontana, 1978.

[5] Elstgeest, J. The right question at the right time. In W. Harlen, Primary science, taking the plunge, W. Harlen, ed, Oxford: Heinemann Educational, 1985.

[6] Good, T.L. \& Bophy,J. Educational psychology, New York: Longman, 1995.

[7] Gott, R., \& Duggan, S. Investigative work in the science curriculum, Bristol, PA: Open University Press, 1995.

[8] Lawson, A. E. Science teaching and the development of thinking, Wadsworth Publishing Company, 1995.

[9] Scott P., Asoko H., Driver R. \& Emberton J. Working from children's ideas: An analysis of constructivist teaching in the context of a chemistry topic, The content of science, London: Falmer, 1994.

[10] White. R. T. \& Gunstone. Probing understanding, London: Falmer, 1992

[11] Chin \& Brown. Student-Generated question: a Meaningful aspect of learning in science, International Journal of Science Education, 24(5), 521 549, 2002.

[12] Cuccio-Schirripa, S. \& Steiner, H. E. Enhancement and analysis of science question level for middle school students, Journal of Research in Science Teaching, 37(2), 210 224, 2000 .

[13] Dillon, J. T. Effect of the question in education and other enterprise, Journal of Curriculum Studies, 14(2), 127-152, 1982.

[14] Dillon, J. T. The remedial status of student questioning, Journal of Curriculum Studies, 20(3), 197-210, 1988.

[15] Gott \& Duggan. The place of investigations in practical work in the UK National Curriculum for Science, Journal of Science Education, 17(2), 137, 1995.

[16] Kim. Development of an evaluation system for defining characteristics related to science at national level, Journal of the Korean Association for Research in Science Education, 0, 85 129, 1997.

[17] Kim, Yeo, Woo. A Study (I) on Students' Questioning Activity in Science Class - The Effect of the Teaching Enhancing Students Questioning, Journal of the Korean Association for Research in Science Education, 19(3), 377 388, 1999.

[18] King, A. Guiding knowledge construction in the classroom: Effects of teaching children how to question and how explain, American Educational Research Journal, 31(2), $338^{\sim} 368$, 1994.

[19] Kwon and Kim. Development of science inquiry ability measurement tools for elementary and middle school students, Journal of the Korean Association for Research in Science Education, 14(3), 1994.

[20] Maskill \& Pedrosa de Jesus.Pupils' questions. Alternative frameworks and the design of science teaching, International Journal of Science Education, 19(7). 781 799, 1997.

[21] Pizzini, E. L. \& Sherpardson, D. P. Students questioning in the presence of the teacher during problem solving in science, School Science and Mathematics, 91, 348-352, 1991. 
[22] Sadker \& Cooper. Increasing student high-order questions, Elementary English, 51, $502 \approx 507,1974$.

[23] Simpson, Ronald D, Anderson, Norman D. Science, students, and schools: a guide for the middle and secondary school teacher, New York: Macmillan, 1981.

[24] Spargo, P. E. \& Enderstein, L. G. What questions do they ask? Science and Children, 43 45, 1997.
[25] Wellington, J, \& Wellington, B. What is a question? The Clearing House, 36(3), 471 472, 196

[26] White, R. T. Learning Science, New York: Basil Blackwell Ltd., 1988.

[27] Woodward. Raising and answering questions in Primary science: Some considerations, Evaluation and Research in Education, 6, $12 \sim 13,1992$. 